\title{
LA "DECLARACIÓN DE MÉXICO" EN LA CONFERENCIA INTERNACIONAL DE POBLACIÓN DE 1984*
}

\author{
VÍCTOR L. URQUIDI
}

El Colegio de México

LA CONFERENCIA InTERnaCIONAL DE POBlaCión, llevada a cabo del 6 al 14 de agosto de 1984 , culminó en una serie de 88 recomendaciones' y en la adopción de la llamada "Declaración de la ciudad de México sobre Población y Desarrollo". 2 Esta declaración fue adoptada por consenso. El documento consta de 23 escuetos párrafos, redactados por un "Grupo de Amigos del Presidente de la Conferencia", tal vez en consulta con otros miembros de delegaciones.

* Trabajo presentado a la Reunión de Presentación y Análisis de los Resultados de la Conferencia Internacional de Población, organizada por el Consejo Nacional de Población, México, D.F., 11 de septiembre de 1984. Versión corregida y actualizada.

1 Véase el documento "Recomendaciones para la ulterior ejecución del Plan de Acción Mundial sobre Población", en Informe de la Conferencia Inter nacional de Población, 1984, del 6 al 14 de agosto de 1984, Naciones Unidas, Doc. E/CONF. 76/19, número de venta: S.84.XIII.8, México, pp. 5-45.

2 Como repetidamente lo hace ver un conocido periodista, no existe ya tal "Ciudad de México", sino sólo el Distrito Federal. Como la Declaración se redactó originalmente en inglés (es decir, es un proyecto que traía la Secretaría General de las Naciones Unidas a través de la Comisión Preparatoria), se quiso traducir "Mexico City". Puede consultarse la versión oficial en español de la "Declaración...", en Informe de la Conferencia Internacional de Población, 1984, op. cit., pp. 1-4. 
Para explicar esta Declaración, quisiera hacer breves consideraciones generales del marco en que debe entenderse y de lo que significó la Conferencia Internacional de Población.

Lo más importante es que en los últimos treinta años se ha creado conciencia en el mundo de que las cifras totales de población no son una simple estadística que se da a conocer en los anuarios de las Naciones Unidas y otras publicaciones, sino que encierran una serie de poblemas sin precedentes en la historia de la humanidad. Los programas de salud llevados a cabo en los últimos treinta a cuarenta años han hecho descender la mortalidad general y, en la mayoría de los casos, la mortalidad infantil, a una velocidad mucho mayor que en cualquier época que hayamos conocido en nuestras lecturas sobre algunos periodos del siglo XIX. Al descender la mortalidad con gran rapidez, se produjo una serie de consecuencias. Una es puramente estadística: aumentó la tasa de crecimiento de la población, porque sobrevivieron más personas; se amplió la pirámide de edades de la población, y la perspectiva de sobrevivencia tendría repercusiones mayores a futuro. Pero también, por lo visto, con la mejoría de la salud, aumentó la natalidad en muchas sociedades. Así que con descenso de la mortalidad y aumentos de la natalidad, o por lo menos mentenimiento de alta natalidad en cierto tipo de sociedades, se produjo lo que antes nos chocaba mucho decir cuando hace veinte años estudiábamos, aqui en México, los problemas demográficos generales y nacionales: la "explosión demográfica", o sea, un aceleramiento rápido de la población mundial a tasas que la historia no conocía, y que significaban, por simple operación aritmética, duplicación de la población mundial en periodos relativamente cortos. Por ejemplo, en 1974 se calculaba que si nada cambiaba, la población mundial se duplicaría en 35 años, y en muchas sociedades, como es bien sabido, la duplicación de la población se produce en 20 , en 25 o en 28 años, $\mathrm{y}$, en ciertas regiones de los países o en algunas zonas urbanas, en 14 o aun menos, según las tasas de incremento, aplicando la fórmula conocida.

Ahora bien, en estos treinta a cuarenta años han ocurrido grandes cambios culturales -y uso la expresión en un sentido muy general, para decir que no es el mismo mundo en que vivíamos antes. Quiero decir con eso que hay actitudes sociales distintas. No somos los habitantes aislados de las zonas rurales. Somos ahora principalmente habitantes de grandes ciudades y experimentamos contacto humano mucho más intenso; tenemos una percepción de que este 
mundo urbanizado es un mundo muy distinto al de hace tiempo, que pequeñas poblaciones se vuelven grandes en pocos años y que la migración lleva a la población de las áreas rurales a conocer también este mundo urbanizado, culturalmente distinto.

Debe mencionarse también que de los años cincuenta para acá, se ha experimentado en el mundo en general un periodo significativo de desarrollo económico, o de prosperidad económica. Podremos discutir quién se llevó la tajada de este mayor pastel económico del mundo. Ciertamente, los países que habían alcanzado ya una etapa avanzada de desarrollo lograron consolidar y mejorar sus niveles de vida material de manera rápida, eliminando prácticamente la condición de pobreza o miseria que en muchos de ellos prevalecía antes de la segunda guerra mundial. En cambio, no todos los países del llamado Tercer Mundo participaron en esta prosperidad mundial; y algunos han salido más bien en peor situación que antes.

Estos impactos de la prosperidad mundial fueron tanto positivos como negativos. Positivos, por lo que significaron en el mejoramiento de los niveles de vida; negativos, porque significaron en muchos casos extracción de recursos del Tercer Mundo para satisfacer necesidades de consumo redundantes, o bien para armar aparatos industriales cuya finalidad principal ha sido prepararse para la guerra nuclear. Estos aspectos han sido, creo yo, negativos en el resto del mundo y son parte de esta nueva situación en que nos encontramos con una especie de desesperación, porque los países del Sur, hoy día más que nunca, están en una situación económica muy desfavorable, se encuentran perplejos ante la incapacidad de los países adelantados para hacer funcionar la economía mundial en forma que beneficie a todos. Los países en desarrollo están ante una perspectiva económica futura no muy favorable, a la par que resulta difícil de frenar el incremento de su población. Es decir, tenemos una situación de incremento demográfico rápido con un grado de subdesarrollo o de dificultad para desarrollarnos en general, en el Tercer Mundo, que no se había registrado antes.

Estos fenómenos y problemas se estudiaron en muchas formas; hubo intentos, hace unos veinte a treinta años, de demostrar mediante ciertos modelos que era mejor invertir en reducir la natalidad que en otras expresiones de la vida social y económica; que un peso invertido en reducir la natalidad rendía más en desarrollo futuro que un peso invertido en cierto tipo de actividades para el desarrollo. Todos esos modelos fueron muy simplistas, muy criticados, pero tuvieron mucho impacto en la opinión pública en el Norte, en ciertos países desarrollados, y tuvieron también impacto en políticas de algunos gobiernos 
del Norte. Esto explica en parte el enfrentamiento a que se llegó en Bucarest en la Conferencia de Población de 1974. ${ }^{3}$

Pudiera ser que muchas personas no estuvieran enteramente de acuerdo con esta interpretación. Tal vez lo que se quiso decir en $\mathrm{Bu}$ carest fue: actuemos en forma pragmática ante este fenómeno global mundial de creciente población a tasas elevadas -que entonces eran del $2 \%$ a nivel mundial, pero cerca de $3 \%$ en los países que contenían algo así como dos tercios de la población mundial- y no actuemos en formas ideológicas que serían en todo caso ahistóricas o bien oportunistas. Ahistóricas, porque no era posible trasladar a 1974 argumentos y situaciones de mediados del siglo XIX; oportunistas, porque siempre había grupos que, aprovechando el tema de población como cualquier otro, deseaban promover ciertas actitudes políticas a nivel internacional.

Cuando hablo de posiciones ideológicas, incluyo lo mismo la izquierda marxista y la posición de los países comunistas y socialistas, que algunos grupos privados de los paises del Norte para quienes una política de descenso de la natalidad era una cuestión casi de fe ante la problemática de la humanidad y, según ellos, una solución a los problemas que vinieran después. Lo cual, por supuesto, no fue aceptado en Bucarest.

Hago estas consideraciones muy generales simplemente para tratar de explicar un poco el ambiente de Bucarest cuando fuimos algunos en la delegación mexicana. La Conferencia de Bucarest tuvo un problema adicional muy complicado: el año de 1974 fue casi el momento del apogeo de la presión política internacional en Naciones Unidas a favor del llamado Nuevo Orden Económico Internacional, encabezada por Argelia y secundada por un grupo muy numeroso de países, entre los cuales figuraban prácticamente todos los del Sur, y desde luego México - los que se llamaron los 77, que ahora son muchos más. En consecuencia, se generó un enfrentamiento entre las posiciones simplistas sobre los problemas demográficos que llevaban algunos países del Norte, digamos Estados Unidos, Suecia, Alemania y las de los promotores del Nuevo Orden Económico Internacional, que era también una posición política que decía: primero resolvamos los problemas económicos internacionales y esto nos va a ayudar para el desarrollo, y después hablemos de población. Este enfrentamiento

3 Véase mi comentario "Danza y contradanza en Bucarest", Plural, vol. IV, núm. 2, 15 de octubre de 1974, pp. 56-60; y un análisis más completo en "Consideraciones acerca de la aplicación del Plan de Acción Mundial sobre Población, Demografía y Economía, vol. X, núm. 1, pp. 31-42. 
fue muy difícil de manejar allá, pero como en toda conferencia internacional, lo último que quiere cualquier delegación importante es salir derrotada de la conferencia. Se busca llegar a acuerdos y consensos, y aunque había esa antinomia de desarrollo versus política de población, es decir, que la fecundidad alta se señalaba como un obstáculo al desarrollo, los partidarios del Nuevo Orden decían que el desarrollo haría bajar la fecundidad. Se llegó, como debe ser en una conferencia de ese tipo en que había finalidades más elevadas que las de mantener posiciones puramente nacionales, al acuerdo que aceptaba que los términos estaban interrelacionados, es decir, que el desarrollo ayuda a variar las tendencias demográficas, y que la acción de los países en materia demográfica podía ser también un auxilio para el desarrollo, por lo que los fenómenos demográficos y los de desarrollo estan intimamente relacionados.

Esta interrelación se afirma y se reafirma ahora en la Declaración de México, pero hay que confesar que son muy pocos los estudios a nivel científico que lo demuestren en forma realmente fehaciente. Sin embargo, se acepta como nuevo dogma que los fenómenos demográficos y los económicos están interrelacionados, y entonces esto, por lo menos, lleva a los gobiernos a no querer tratar unilateralmente ninguno de los dos. Sería tan insensato querer hacer desarrollo olvidándose de las tendencias demográficas, como querer hacer política demográfica sin pensar que ésta es parte, como ya se acepta recientemente, de una política de desarrollo.

Además de esta afirmación, Bucarest creó obviamente muchísima mayor conciencia internacional; la creó a nivel de los gobiernos, así como a nivel de Naciones Unidas como tema permanente de examen en la Asamblea General y en todos los diferentes organismos del sistema. Además, el Fondo de las Naciones Unidas para Actividades en Materia de Población, junto con el Departamento de Población de las Naciones Unidas, adoptaron como objetivo concreto examinar las tendencias y revisar los resultados de los cambios en las políticas demográficas, y proveer cooperación a todos los países que lo solicitaren en una gran diversidad de asuntos referidos a población, desde investigación médica hasta social y demográfica, formulación de políticas de población, aplicación de distintos aspectos de la política, etcétera.

En Bucarest quedó también establecido clarísimamente, y ahora reafirmado, que la política demográfica debe ser una política soberana de las naciones. No hay ningún organismo internacional que pueda dictar a un país su política demográfica, como tampoco ningún país la puede imponer a otro. Es un asunto totalmente reservado a la decisión soberana de los países. Se hizo también en la Conferencia de 
1974 mucho hincapié -hoy recalcado-, en el respeto a los derechos humanos de la persona y de la familia en materia de decisiones en cuanto a las variables demográficas, es decir, frente a la natalidad y principalmente frente a la migración. Además, salió de Bucarest muy claro que el tema demográfico sería en adelante (y lo sigue siendo) parte del enfrentamiento Norte-Sur, puesto que el tema del Nuevo Orden Económico Internacional continúa vigente.

¿Qué ha pasado después de Bucarest? Los datos están en los documentos que se presentaron a la Conferencia de México. Voy a citar muy brevemente lo más significativo a mi juicio. En efecto, hubo un descenso de la tasa de incremento anual de la población mundia!, de 2.03 a 1.67 por ciento -más o menos lo que se preveía entonces-, o sea que se ha cumplido la proyección; pero este descenso, si se examinan las cifras por continentes y por países importantes, se produjo como resultado de una política de población muy intensa, dirigida a bajar la natalidad, de la República Popular China, la cual no se preveía muy claramente en Bucarest en 1974; en segundo lugar, la de países como Corea y la India; luego el caso de México, que representa un descenso muy apreciable de la fecundidad entre 1974 y 1984, o sea durante el periodo en que se pusieron en ejecución la política demográfica y las actividades del Consejo Nacional de Población. Debe mencionarse además una serie de países menores que no influyen mucho en el total, pero cuyos descensos son significativos; por ejem. plo, la tasa de incremento demográfico bajó muy considerablemente en países como Cuba, Panamá, la República Dominicana. En cambio, se redujo en mucho menor grado o muy poco en otros países latinoamericanos - Brasil, en particular- y desde luego apenas unas fracciones decimales en países del sudeste de Asia y Asia meridional. En África se produjo un aumento casi generalizado de las tasas de incremento de la población; en muchos de estos paises, el incremento po. blacional rebasó el 3.5\%, y se cita uno, Kenia, donde llegó a ser de 4\%. En África ha empezado a bajar la mortalidad, pero no la natalidad, salvo casos muy dispersos. En los países del Norte, sobre todo en Europa tanto occidental como oriental, ha habido o bien estancamiento de la población en este periodo de 10 años o descensos absolutos de la misma. En Canadá y Estados Unidos los incrementos han sido moderados, es decir, de menos de $1.5 \%$ al año, no obstante la migración hacia esos paises. 4

4 Sobre lo anterior, véase Naciones Unidas, Review and Appraisal of the World Population Plan of Action-Report by the Secretary General, Doc. 
El cambio en las cifras no debe verse sólo globalmente, sino por regiones, porque esto permite detectar que la explosión demográfica está por producirse en África, pues llevará mucho tiempo cambiar las tendencias de los países más importantes de ese continente. En Europa, y en general en el Norte, los países desarrollados han entrado ya en una etapa que ellos llaman de envejecimiento de la población, es decir, que tiende a la no renovación de su población. Los países de América Latina y Asia tienen situaciones muy variadas que dependen esencialmente de sus políticas de planificación familiar, de las cuales la que llega a los extremos más fuertes es la de la República Popular China, y entre las cuales destacan por sus métodos no coercitivos la política mexicana y la de algunos otros países del área latinoamericana.

Las encuestas llevadas a cabo por Naciones Unidas demostraron que en el decenio aumentó el número de gobiernos que definieron sus políticas de población y llegaron a la conclusión de que las tendencias demográficas de sus países empezaban a ser motivo de preocupación para sus políticas de desarrollo. Yo agregaría que se difundió también entre el público un conocimiento más complejo, más exacto, más equilibrado de la problemática demográfica en muchos de los países tanto del Norte como del Sur, y que muchos de los grupos que adoptaban posiciones demasiado simplistas hace diez años han entendido gradualmente que la problemática demográfica es mucho más complicada. 5

Al mismo tiempo, en el periodo 1974-1984 surgieron problemas que, si bien se previeron en Bucarest, han adquirido acentos más fuertes; o bien se ha profundizado en muchos de sus aspectos. Entre ellos, la migración interna, es decir, la migración del campo a las ciudades (principalmente). Las tasas de urbanización y la preocupación por el crecimiento de las ciudades se han agudizado en este periodo y ha habido también mayor conciencia de lo que significan. También se ha producido mucha más migración entre áreas rurales de lo que podía haberse imaginado en el tiempo de la Conferencia en Bucarest.

En segundo lugar, la migración internacional, tanto la voluntaria

E/CONF. 76/PC/40, 1o. de diciembre de 1983, especialmente los párrafos 115 a 130 y el cuadro 1 .

5 Un amigo soviético, especializado en América Latina, me confesó hace cuatro años que tenía yo razón al insistir en que un crecimiento demográfico del 3\% anual era excesivo; antes lo tomaba él como factor positivo para el desarrollo. Mucha gente cree aún que " 3 " es una tasa despreciable, una cifra sin consecuencias. 
como la forzada o involuntaria, ha adquirido proporciones muy grandes en casi todas las regiones, entre Sur y Norte y entre Sur y Sur, como lo sabemos bien por las migraciones al Cercano Oriente y otras dentro de Asia y en el interior de África y de América Latina. Ha surgido también el problema de las poblaciones refugiadas por conflictos bélicos, por actos políticos, por expulsiones de áreas que consideraban suyas a otras, y este problema tampoco puede soslayarse. Se ha hecho más hincapié en los problemas de impacto ecológico de ciertas densidades demográficas, sean urbanas o rurales, por erosión de los suelos y por destrucción de los bosques en grandes partes del Tercer Mundo.

En estos diez años, se han producido en materia demográfica desequilibrios más marcados entre algunas regiones de lo que se suponía antes. Las preocupaciones globales, es decir, del mundo en su conjunto, han adquirido también mayor concreción; no es sólo cuestión de cifras, sino de pensar hacia dónde se va en el futuro. En los años setenta empezaron las publicaciones que auspiciaba el Club de Roma, después revisadas y corregidas en muchos otros estudios. Podrá criticarse mucho de lo simplista de la posición inicial del Club de Roma, 6 pero el número de estudios que reflejan preocupación por lo que va a ser el mundo el año 2000 , o más allá, es creciente en todos lados. No obstante los distintos sistemas sociales y políticos, los países de responsabilidad ante el futuro de la humanidad tienen grupos de estudio de prospectiva en la cual figura como dato inevitable el de la población. Cuando se dice que la población del año 2000 excederá ligeramente de 6000 millones, la siguiente pregunta es: $¿ y$ en el año 2010 y el 2020 y 2050 , a dónde va a terminar esto, y cuál es el límite de recursos o de capacidad de las sociedades para organizarse, para hacerles frente a poblaciones de esa dimensión futura? Y no se puede decir simplemente: eso les tocará a las generaciones futuras -que discutan y resuelvan como puedan. Este tipo nuevo de reflexiones se ha extendido mucho y creo que estaba en el ambiente en las conferencias de este tipo como la que hemos tenido en México.

\section{II}

Ahora paso a la Conferencia de México para puntualizar lo que a mi juicio son puntos sustantivos importantes. ¿Por qué se llevó a cabo la conferencia en México? Porque había que llevar a cabo una conferencia diez años después de Bucarest, y México ofreció la sede, y

6 Dennis L. Meadows et al., Los limites del crecimiento, México, Fondo de Cultura Económica, 1972. 
tal vez Naciones Unidas pensó que el caso de México era uno de mucho interés para el resto del mundo por la forma en que se instrumentaron las políticas de población a partir del año de 1974 , o bien que el contacto con la sobrepoblada zona metropolitana de la ciudad de México haría reflexionar a las delegaciones todavía renuentes a adoptar políticas de población.

La estrategia en esta Conferencia, hasta donde yo la percibí, consistió en no reabrir el debate de Bucarest, el de una política unilateral demográfica versus una política de desarrollo, sino más bien reafirmar la idea de la interrelación; en otras palabras, continuar dando validez al Plan de Acción Mundial que se elaboró y se aprobó en Bucarest.7 Esta estrategia, por los documentos que he visto, me parece que también tendía a acentuar algunos puntos ya incluidos en el Plan de Acción Mundial, pero que quizás necesitaban mayor concreción, a saber:

Primero, la formulación y aplicación de políticas de población en el sentido integral amplio que se difinió en ese documento.

Segundo, mayor atención, por la constante violación que ocurre en esta materia, a los derechos humanos, lo cual tiene conexión con algunos programas de planificación familiar en que evidentemente se dio muy poca consideración al derecho de decisión de la familia o se usaron incentivos o métodos de inducción a aceptar la planificación familiar que eran violatorios de derechos o de la dignidad humana (casos de la India y la República Popular China).

Tercero, el énfasis mucho mayor en los temas relativos a la condición de la mujer.

Cuarto, el tener en cuenta distintas modalidades de la planificación familiar. Se hablaba hace diez años de planificación familiar como si fuera la misma cosa en cualquier parte del mundo, en cualquier país, en cualquier región de un país. El Fondo de Población de Naciones Unidas y otros organismos han tenido ya en cuenta la enorme diversidad de modalidades que se requieren, entendida la planificación familiar no como simple uso de anticonceptivos, sino como la conciencia, a nivel de la familia y de los individuos, de lo que deben ser la dinámica y el ciclo de vida de la familia. Esta diversidad de modalidades de planificación familiar se empezó a observar en los últimos años, y posiblemente haya salido reforzada de esta Conferencia de México.

7 Véase mi "Desandanzas poblacionales - de Bucarest a Tlatelolco", Vuel. ta, núm. 98, enero de 1985, pp. 22-24. 
Quinto, más atención a los impactos ecológicos (que ya he mencionado).

Sexto, mucha más preocupación por la migración internacional y también por la migración interna y su consecuencia poderosa que es la alta concentración urbana.

Habia también algunos problemas especiales que iban a surgir en esta Conferencia de México. Por ejemplo, el del aborto. El tema del aborto ha sido muy debatido; en muchos países europeos, aun los de fuerte tradición católica, el aborto se ha despenalizado o legalizado. En Estados Unidos, se siguió al principio una política muy liberal y últimamente se ha ido restringiendo. Se producen cambios en la política respecto al aborto que reflejan a su vez cambios en las condiciones culturales y sociales de los países. Era éste un tema que venía discutiéndose, pero que no afloró muy abiertamente en la Conferencia de México, aunque se aprobaron recomendaciones sobre al asunto. Se trató en forma muy específica, y sobre todo, se puso más énfasis en que el aborto despenalizado o legalizado no debe ser un medio de planificación familiar, sino un remedio a una situación social y familiar ante una demanda específica que se manifiesta, y que, cuando no está legalizado el aborto, se convierte casi siempre en aborto clandestino que pone en peligro la vida de la mujer. La planificación familiar es otra cosa, es lo básico, y el aborto no es parte de la planificación familiar.

Como tema especial, estuvo presente el problema de África, que obviamente no se iba a poder discutir específicamente en la Conferencia de México, porque se tratarían problemas de orden muy general; mas la preocupación por la futura explosión demográfica de Âfrica sí estaba en el ambiente: poco después del año 2000 , si no se presentan cambios importantes y aun suponiendo algunos descensos de la fecundidad, la población de África excederá de 1000 millones de habitantes, mientras que América Latina, que antes se consideraba como el área de explosión demográfica, va a tener bastante menos de 600 millones en esa fecha. Esto es motivo de preocupación en función de los recursos con que cuenta África, sus posibilidades de alimentación propia, la salud de sus habitantes, y sobre todo, en general, la organización de esas sociedades para dar un mínimo nivel de vida adecuado a sus habitantes.

Otro tema especial que no se iba a discutir en México, pero que estaba ya en el ambiente, es el problema de lo que llamo aquí sintéticamente "la fecundidad musulmana". Es decir, los países islámicos casi no han hecho nada en materia de planificación familiar. Las tasas de incremento demográfico se sostienen o casi no han bajado, y en 
las poblaciones islámicas minoritarias de muchos países se advierte claramente que su fecundidad específica sigue siendo muy alta y que va a afectar, en consecuencia, la composición interna de las poblaciones. Casi no ha sido aplicada en estas poblaciones la planificación familiar.

Otro punto muy específico que debe mencionarse es el de la posición endurecida de la Santa Sede, posición ideológica muy dura, más rígida que en Bucarest, en contra de la anticoncepción y en consecuencia en contra de la planificación familiar con uso de anticonceptivos que la investigación médica ha hecho viables. Esta posición se ha repetido en todas partes y puede haber influido en la opinión pública en muchas zonas del mundo.

Otra posición ideológica endurecida, y curiosamente en un sentido inesperado, es la de la Casa Blanca de Estados Unidos, que no sólo se opuso en forma muy clara al aborto que ya se había liberalizado en ese país, sino que adoptó una posición frente a los programas de planificación familiar y a los organismos de las Naciones Unidas según la cual se amenazaba con no seguir dando apoyo a esos programas si entre ellos figurara algún subprograma relativo a la legalización, liberalización o despenalización del aborto. Esta posición cambió un poco hacia el final, poco antes de la Conferencia, pero parece estar claramente definida ( $y$ después de la conferencia se ha puesto en práctica, condicionando a ella los subsidios a los organismos no gubernamentales y las aportaciones bilaterales y multilaterales).

Un tema que venía creando problemas, pero más bien de orden político, aunque con consecuencias sociales y humanas terribles, es el del desplazamiento de habitantes de los territorios ocupados, especialmente en el Cercano Oriente, o sea la situación en que quedan los habitantes de territorios ocupados durante los conflictos bélicos y que siguen ocupados, en la opinión de los países árabes, en forma ilegal. Éste-fue uno de los asuntos delicados que se trataron en la Conferencia de México, pero que al final afectó unas cuantas frases o palabras de redacción de una recomendación, pues su foro sería más bien la Asamblea General de Naciones Unidas.

Todavía otro tema que tampoco se iba a tratar en forma generalizada, pero que llama la atención, es el de las consecuencias del envejecimiento de la población en los países del Norte por la mucha mayor población de personas de más de 65 años y las consecuencias que ello tiene en la vida familiar, en las distintas estructuras familiares, $y$ en los servicios de seguridad social.

Finalmente, para la Conferencia de México se presentaba de nuevo, pero creo que se soslayó bastante en las discusiones, la visión del 
futuro a la que ya he hecho mención; las proyecciones a futuro más allá del año 2000 , las nuevas estructuras entre regiones y entre continentes, el problema masivo que va a significar a futuro el subempleo en los países del Tercer Mundo, mientras no se logren organizar las economías en forma que permita absorber la creciente fuerza de trabajo de esos países que generalmente sigue creciendo a una tasa superior a la del incremento demográfico. En 20,30 o 40 años la fuerza de trabajo será en muchas sociedades el doble de lo que es actualmente. Cuesta un gran esfuerzo tratar de imaginar y estudiar todos los complejos aspectos que significa eso, con los cambios internos y estructurales que se requieren.

La Conferencia de México puede resumirse como un intento de acentuar un nuevo "dogma pragmático" -si se puede usar esa expresión contradictoria - de interrelación de los temas demográficos con los de desarrollo, así como de encauzar las políticas nacionales de población integradas en esas estrategias, o en los planes de los países que los tengan, y de reforzar el apoyo internacional del sistema de las Naciones Unidas a los países que lo soliciten para llevar a cabo sus planes y sus programas nacionales.

Secundariamente, la Conferencia ha creado más conciencia a nivel internacional de esta problemática, y eso se ha logrado, en gran parte, porque no hubo enfrentamientos importantes respecto al tema central de la Conferencia. Se avanzó hacia este nuevo pragmatismo que yo menciono, aunque claro que hubo algunas posiciones ideológicas de ciertos países y de ciertos grupos.

\section{III}

Por último, cabe analizar brevemente la "Declaración de México". Como es un documento breve, se puede leer con facilidad. 8 Varios párrafos iniciales se refieren a generalidades. En el párrafo 6 se da, sin embargo, una visión un tanto pesimista, la cual encuentro algo contradictoria con mucho de lo que se dijo en la Conferencia y que está en el resto de la propia Declaración. Cito apenas dos oraciones del párrafo 6, que dicen: "Desde la Conferencia de Bucarest la tasa de crecimiento de la población mundial ha disminuido del 2.03 al 1.67 por ciento anual", y a continuación: "En el próximo decenio la tasa de crecimiento se reducirá más lentamente". Es decir, se está dando por supuesto que va a ser cada día más difícil hacer bajar la fecundidad en el mundo o en determinadas regiones; estamos desde

8 Véase el documento citado en la nota 2. 
luego ante todas estas contradicciones por lo de África, por lo de los países islámicos, por lo de algunos países latinoamericanos, frente a las bajas fuertes que ya han ocurrido en la República Popular China y en otros países de Asia. Tal vez se piense aquí -no está dicho- que China siga haciendo bajar su natalidad como lo ha hecho en los últimos diez años, pero que será un esfuerzo mucho más complicado. No obstante, se da la impresión de que estamos ante esa problemática global irremediable de que el mundo va a llegar a tener 6100 millones de habitantes a fin de siglo y que, como dice el documento, "la tasa de crecimiento se reducirá más lentamente".

Esto aparece también en el párrafo 7 , que alude al tamaño de la familia en los países en desarrollo: "Ello es causa de preocupación, ya que las presiones sociales y demográficas pueden contribuir a que se mantenga la amplia disparidad en cuanto a bienestar y calidad de vida que existe entre los países en desarrollo y los países desarrollados". Insisto en que ésta es una visión algo pesimista del futuro de la humanidad.

Y esto resurge en el párrafo 22, el penúltimo, donde dice, refiriéndose a Bucarest: "En la Conferencia de Bucarest se dio a conocer al mundo la gravedad y la magnitud de los problemas demográficos y su estrecha relación recíproca con el desarrollo económico y social". En estos párrafos las siguientes palabras empleadas tienen significado: preocupación, presiones sociales, gravedad, magnitud, etcétera.

A partir de allí, la Declaración toma una serie de temas del Plan de Acción Mundial de 1974 y de las Recomendaciones de la reciente Conferencia. Primero, en el párrafo 8 , subraya la necesidad de integrar la política de población con la planeación del desarrollo. Eso está dicho clarísimamente, y está dicho no obstante la posición que traía uno de los países importantes del Norte, los Estados Unidos, en el sentido de que la libre empresa y el libre desempeño de las fuerzas del mercado son la forma correcta de abordar los problemas del desarrollo. Aquí se dice "planificación del desarrollo", y se afirma que se debe dar "prioridad a los programas de acción que integren todos los factores básicos de población y desarrollo".

Inmediatamente se pasa al viejo tema de Bucarest -ahora reforzado-, o sea la conveniencia de la planificación familiar para los países que deciden que ése es un problema que deben abordar (puesto que se respeta la soberanía); pero se expresa que "los programas de planificación de la familia han logrado reducir la fecundidad con costo relativamente bajo", y se añade que "los países que consideren que su tasa de crecimiento demográfico obstaculiza sus planes nacionales de desarrollo deben adoptar programas y políticas apropiados en ma- 
teria de población". Esto se había dicho ya en Bucarest; es una simple reiteración.

Al mismo tiempo se hace énfasis en la necesidad de seguir haciendo bajar la mortalidad, en especial la infantil, y esto se afirma precisamente en el párrafo 9 y de nuevo en el párrafo 15 , en donde se menciona la posibilidad de lograr "una revolución en la supervivencia infantil"; es decir, mediante cambios en los sistemas de salud materno infantil, la lactancia materna, nutrición adecuada para los niños, el agua no contaminada, terapias de rehidratación oral y el espaciamiento de los nacimientos.

Se subraya en el párrafo 10 la necesidad de orientar la planificación familiar hacia las comunidades, las familias y las personas. Se hace énfasis precisamente en la participación de individuos, familias y comunidades. Es decir, la planificación familiar no debe de ser una imposición, sino que deberá ser -yo le llamo- un cambio culturalsocial con participación de los interesados. Se acentúa también la conveniencia de crear mayor conciencia social acerca de los problemas demograficos.

En seguida, en el párrafo 11, se expresa sintéticamente lo que aparece en las Recomendaciones sobre integración de la mujer al desarrollo, y no creo necesario hacer ninguna explicación adicional, porque están bien formuladas las Recomendaciones y es un capítulo especial de las mismas.

En los párrafos 12 y 13 se vuelve a hablar de la necesidad del acceso a la planificación familiar y a sistemas eficaces de la misma. Se dice que esto se justifica para evitar una elevada fecundidad no deseada, y que éste es un derecho fundamental. Como se sabe, esto aparece ya en la legislación de muchos países; inclusive en México el artículo 4o. Constitucional establece el derecho de la persona (y en consecuencia de la pareja) a decidir libremente el número y el espaciamiento de sus hijos. Es un derecho fundamental. Sin embargo, lo interesante es una frase en el párrafo 13 donde se hace ver que ésta es una cuestión no sólo familiar -cito- sino de "obligaciones hacia la comunidad". Creo que esto aparece más concreto que en los documentos de Bucarest. Es decir, es una responsabilidad comunitaria, el pensar en la fecundidad y en la significación social de la elevada fecundidad no deseada.

También se hace alusión en los párrafos 13 y 14 a la necesidad de mejorar los métodos de planificación familiar, de promover las investigaciones necesarias y de hacer seguros y eficaces esos métodos.

A continuación, el documento pasa a tratar algunos de los aspectos demográficos globales y regionales con vistas al año 2000 y a los 
cambios de estructuras que puedan esperarse o puedan considerarse necesarios. En el párrafo 13 se hace referencia explícita al número de mujeres que estarán en edad de procrear en el año 2000: $1600 \mathrm{mi}$ llones de mujeres, de las cuales 1300 estarán habitando países en vía de desarrollo.

En el párrafo 16 hay una referencia al problema de la población joven, es decir, a las tasas de incremento, al cambio en la base de la pirámide de edades y en los números reales de población joven, y se hace referencia explícita a la necesidad de "programas especiales para responder a sus necesidades y aspiraciones, incluido el empleo productivo". 9 En el mismo párrafo, paradójicamente, se habla del envejecimiento de la población de los países que están experimentando ese proceso, que es un problema completamente distinto y que suscita una serie de programas especiales de otro orden para hacerle frente. Pero en fin, hay esa visión de futuro respecto al rejuvenecimiento de poblaciones de los países del Tercer Mundo y su impacto en las necesidades de empleo y otras, y al envejecimiento de los países maduros del Norte.

En el párrafo 17 se hace referencia concreta a la población urbana de fines de siglo. Se estima que habrá 3000 millones de personas, o sea el $48 \%$ de la población mundial, "viviendo en ciudades, con frecuencia en ciudades muy grandes". Se menciona la necesidad de estrategias de desarrollo urbano y rural integrado como parte fundamental de las políticas demográficas. Sin embargo, las Recomendaciones sólo contienen un párrafo, el número 43 , en el que se menciona el desarrollo rural. 10 Debe recordarse que en el Plan de Acción Mundial de Bucarest casi no figuraba ninguna referencia al desarrollo rural como elemento importante para una política demográfica o para hacer frente a estas tendencias agobiantes de urbanización que se están previendo ya.

En seguida, el párrafo 18 hace alusión a los movimientos migratorios internacionales y subraya la necesidad de salvaguardar los derechos individuales y sociales que se pisotean frecuentemente en estos movimientos, sean voluntarios o involuntarios. Se insiste en que "se requiere la cooperación de los países de origen y destino y la ayuda de las organizaciones internacionales" para resolver estos problemas de la violación de los derechos fundamentales de las personas que partici-

9 La frase "incluido el empleo productivo" fue incorporada a última hora a instancia de un delegado mexicano, pues la palabra "empleo" -añadiríamos, el concepto mismo- no había aparecido en ninguna de las versiones anteriores.

10 Véase el documento citado en la nota 1. 
pan en los movimientos migratorios. Creo que es una frase un poco ambigua, pero supongo que es una referencia a la necesidad de arreglos bilaterales y no necesariamente convenios internacionales o multilaterales.

En el párrafo 19 existe la expresión de un "compromiso político" de los países firmantes o aceptantes de la Declaración para formular programas demográficos y asignar los recursos necesarios para la ejecución de esos programas. Dice así: "El compromiso político de los jefes de Estado y de otros dirigentes y la voluntad de los gobiernos para tomar la iniciativa en la formulación de programas demográficos y asignar los recursos necesarios son decisivos para la ulterior ejecución del Plan de Acción Mundial". La palabra "ulterior" es un poco engañosa porque a nosotros, de habla española, nos da idea de algo que se va a hacer quién sabe cuando, pero en inglés se escribe further development, y los traductores de Naciones Unidas han inventado que further es "ulterior". Lo que el texto quiere decir es: continuación de los esfuerzos, más que dejar para un plazo ulterior.

También se habla en el párrafo 19 de "asegurar la coordinación de la asistencia internacional en el plano nacional". Es decir, en los países que reciban diversas cooperaciones, que se coordinen adecuadamente en lo interno, porque a veces resultan un poco contradictorias o competitivas entre sí.

E1 párrafo 20 expresa la necesidad de la cooperación internacional, que era uno de los objetivos principales de la Conferencia y la necesidad de -cito- "aumentar los recursos para las actividades en materia de población", o sea aumentar las aportaciones al Fondo de las Naciones Unidas para Actividades en Materia de Población, que ha jugado un papel muy destacado en todos los programas internacionales. Pero esto no excluye, naturalmente, otras formas de prestar cooperación internacional -por ejemplo, de gobierno a gobiernoen materia de población. En todo caso, el párrafo reafirma que "el sistema de las Naciones Unidas debe seguir cumpliendo sus responsabilidades vitales". (Así lo esperamos todos.)

Por último, el párrafo 21 es una referencia a las organizaciones no gubernamentales, a las que se les reconoce que desempeñan una función importante en la ejecución del Plan Mundial de Bucarest, y seguramente en la aplicación de las Recomendaciones aprobadas en México, que merecen el estímulo y el apoyo de los gobiernos y las organizaciones internacionales. Se exhorta a "los parlamentarios, a los dirigentes de las comunidades, a los científicos y a los comunicadores $\mathrm{y}$ a otras personas en posiciones influyentes, a que ayuden en todos los aspectos de los trabajos relacionados con población y desarrollo". 
Deben señalarse también omisiones, y quisiera enumerar algunas. Por ejemplo, esta Declaración atribuye poca importancia a las causas del incremento poblacional rápido, especialmente al problema de la alta fecundidad, que son causas todavía culturales, de falta de cambio social, de poca organización para cumplir programas, deficiencias de los programas de salud, etc. Quizá no se podía entrar mucho en esto, pero se puede reafirmar por el lado positivo, y está en las $\mathrm{Re}$ comendaciones.

La Declaración no contiene ninguna referencia a diferenciaciones regionales o a casos regionales, que por supuesto no se podían mencionar.

La palabra "empleo", como mencioné antes, aparece una sola vez en todo el documento, aunque se lee "desempleo" en el párrafo 9 -y cito esto no porque sí deba aparecer una o más veces la palabra "empleo", sino porque considero que en una visión de futuro y sobre todo en los países en vía de desarrollo, en un diagnóstico de lo que pueda ser el desarrollo futuro, el problema del empleo será absolutamente central y se está tratando sobre él como parte esencial de todos los programas de desarrollo del mundo, pues el objetivo es precisamente dar empleo, dar ingresos para hacer posible una vida mejor.

Contra lo que podia haberse esperado, no hay mucha mención en el documento de los problemas de cooperación económica y financiera internacional para el desarrollo, como sí lo hubo en Bucarest, y como podía haberse esperado en México, debido a la crisis internacional. Sin embargo, se encuentran algunas alusiones en el preámbulo de las Recomendaciones.

Aparecen sólo dos usos de la expresión "calidad de vida" en la Declaración -párrafos 5 y 7-, pese a que todas las discusiones de los últimos cinco $\mathrm{u}$ ocho años han puesto creciente énfasis en "calidad de vida" como elemento esencial de lo que debe ser el objetivo de una política de desarrollo y de una política demográfica.

Desde luego, no se encontrará en la Declaración la palabra "aborto"; la controversia sobre el aborto no se llevó a la Declaración, pero sí aparece en la recomendación 18, que provocó aguda discusión entre delegados de distintos países según su posición, inclusive los de Estados Unidos, la Santa Sede, Suecia y otros.

Quedó fuera también en la Declaración algo que se evitó esencialmente en el preámbulo de las Recomendaciones, pero que se trasluce en una de ellas: la posición de la Casa Blanca, de la filosofía "reagapópica" (del inglés, que aquí invento, Reagapopics, correspondiente al Reaganomics), según la cual con sólo dejar todo al libre ejercicio de las fuerzas del mercado y a la libre empresa se logran resultados 
que alivian el problema demográfico. En consecuencia, no se necesita planificación del desarrollo ni ninguna otra cosa que se le parezca. Pero se evitó eso en la Declaración, porque era la posición de un solo país. aunque tampoco se ahonda mucho en el tema "desarrollo versus población".

No se incluye una sola palabra sobre fomento de la investigación en ciencias sociales, que nos preocupa a los que estamos en ese campo. Con relación a temas de población y desarrollo, hay una brevísima referencia en una de las recomendaciones de las 88 aprobadas, como hubo breve referencia en el Plan de Acción Mundial. Los que nos interesamos en ese tema debemos seguir insistiendo en que ascienda en importancia en declaraciones futuras.

Como conclusión, me parece que la Declaración de México es un documento que todos los países pueden aceptar, y éste era tal vez el objetivo del mismo. Para los que aún no ejecutan políticas demográficas o de población integradas adecuadamente a sus políticas de desarrollo, es una guía, pero una guía blanda, y sólo los países que tengan conciencia de su problema de población frente a sus proble. más de desarrollo o con relación a éstos, y deseen implementar una política integrada, encontrarán la guía adecuada en este documento. Cada país tendrá que profundizar en los temas planteados, interpretar la Declaración según sus necesidades y definir sus propias acciones coordinadas. 